\title{
Social Tools And Rules for Teens (The START Program): Program Description and Preliminary Outcomes of an Experiential Socialization Intervention for Adolescents with Autism Spectrum Disorder
}

\author{
Ty W. Vernon ${ }^{1} \cdot$ Amber R. Miller ${ }^{1,2} \cdot$ Jordan A. Ko ${ }^{1} \cdot$ Victoria L. Wu $^{1,3}$
}

(C) Springer Science+Business Media New York 2016

\begin{abstract}
Experiential learning is an essential process in the development of core social competencies. Unfortunately, adolescents with autism spectrum disorders often do not possess the prerequisite skillset and motivation to sustain the level of social immersion needed to benefit from this learning process. These persisting social vulnerabilities can limit their long-term relational success and associated quality of life, creating a need for comprehensive social programming. This paper describes a multi-component socialization intervention that simultaneously targets motivational, conceptual, and skill deficits using a hybrid experiential/didactic treatment approach. Evidence of social competence improvements was noted in survey and live conversational measures, indicating that the START program may hold promise as a method for improving the social success of participating adolescents with ASD.
\end{abstract}

Ty W. Vernon

tyvernon@education.ucsb.edu

Amber R. Miller

amucsb@gmail.com

Jordan A. Ko

jordanalexisko@gmail.com

Victoria L. Wu

victoriawu2011@gmail.com

1 Department of Counseling, Clinical \& School Psychology, Koegel Autism Center, University of California Santa Barbara, Santa Barbara, CA 93106-9490, USA

2 Present Address: Children's Hospital Los Angeles, Los Angeles, CA, USA

3 Present Address: University of California San Diego Medical School, San Diego, CA, USA
Keywords Adolescents - Autism spectrum disorders · Experiential learning $\cdot$ Social skills training $\cdot$ Social competence

\section{Introduction}

Experiential learning is the process of learning through authentic experiences and subsequent reflection on these encounters (Kolb 2014). This active learning immersion may offer unique benefits to participants, as they can make discoveries and experiment with responses and strategies firsthand, instead of just passively benefitting from other individuals' stories, experiences, and lessons. Additionally, individuals are exposed to the full range of dynamic variables and complexities that accompany a real-world experience, most of which is inevitably lost when information must be consolidated and summarized into a format suitable for a didactic instructional lesson.

Experiential learning theory is conceptualized as a four stage learning process (Kolb et al. 2001): (1) A concrete experience serves as the stimulus for (2) reflective observation on what is functionally working or failing to work in the learning context, which (3) solidifies one's abstract conceptualization of a given phenomenon. Based on this accrual of knowledge, the individual is able to engage in (4) active experimentation to hone one's knowledge base and associated skill set, which is then applied to future concrete experiences.

When applied to socialization and conversational competence, experiential learning is heavily reliant on sustained immersion in an appropriate social environment (Baker et al. 2002). Mapped onto the four stage experiential learning process, interactions with others provide an experiential stimulus that allow individuals to reflect on 
their interpersonal successes and failures, improve their understanding of successful social strategies, and modify subsequent social bids to improve the likelihood of success in future engagements. For the general adolescent population, the accumulation of these interactions appears to be crucial for establishment of social competence and seems to be predicated upon two interrelated factors: (a) the willingness (or motivation) of the individual to engage with available social partners and (b) the willingness of these partners to be responsive to the social bids of that individual.

As an initial requirement, the individual must have adequate motivation to engage in social interaction. There must be a personally compelling rationale for social participation, whether it is a desire to forge new relationships, obtain acceptance into a social club or group, and/or access some extrinsic incentive or ulterior motive (Ojanen et al. 2010). Additionally, there must be confidence that the quality of the individual's interactions will result in a positive social exchange. Without a clear investment in the social outcome, the individual will not have an adequate incentive to fully engage with their social partners and benefit from the natural lessons inherent within the interaction.

Likewise, peer acceptance is another pre-requisite for experiential social learning. Without a group willing to actively engage the individual, he or she is left without a proper social context to benefit from associated learning opportunities (Ollendick et al. 1992). Herein lies the cyclical nature of the problem: individuals with the most significant social vulnerabilities are frequently ignored or even actively rejected by their peers, preventing them from accessing the very social context needed to enhance their skillset to the minimum threshold to prevent future rejection (Parker and Asher 1987). Thus, such individuals are left without an adequate means to obtain this crucial social traction unless both individual and contextual factors are targeted simultaneously. This dilemma may be particularly relevant for the significant social vulnerabilities inherent among adolescents with autism spectrum disorders (ASD).

Adolescents with ASD often have a skill set that is inadequate for the increasingly complex social situations they face as young adults (Gutstein and Whitney 2002; Hendricks and Wehman 2009). Even high-functioning individuals are often at odds with this frequently used descriptive label. As adolescents with ASD transition to adulthood, their social vulnerabilities persist and the majority continue to live with their parents or other caregivers, remain unemployed or underemployed, and rely on the financial support of others (Engström et al. 2003; Howlin 2000). Additionally, this population is at significantly higher risk for developing depression or anxiety (Church et al. 2000; Ghaziuddin et al. 2002; Kim et al. 2000), as greater cognitive awareness also extends to the recognition of limited social success relative to the general population.

In addition to the aforementioned motivational and contextual socialization barriers facing the general adolescent population, individuals with ASD also experience a myriad of other challenges, including limited social conversation, theory of mind/empathy, abstraction, and agency detection skills (Baron-Cohen 1995; Bauminger 2002; Blair et al. 2002; Starr et al. 2003). While many of these vulnerabilities appear to be linked to the inherent neurobiology of the disorder (DiCicco-Bloom et al. 2006), there is also growing acceptance of the hypothesis that the initial symptoms of autism contribute to more pronounced vulnerabilities later in life due to the transactional nature of development (e.g. Jones and Klin 2009). The ultimate social outcomes of individuals with ASD appear to be a confluence of their initial symptom profiles, the availability and sustainability of suitable social experiences, and the quality of available intervention efforts.

Structured social skills intervention models have been growing in popularity as a means to address the core area of socialization difficulties of adolescents with ASD. There is a growing body of evidence supporting the effectiveness of these group socialization efforts (Miller et al. 2014; National Autism Center 2009; Reichow et al. 2012). However, there is currently very limited research available on the potential benefits of experiential social learning within a social skills intervention context.

Many existing social skills intervention programs focus primarily on didactic lessons. These approaches rely on systematic instructional methods to address many of the social vulnerabilities associated with ASD (e.g. conversation skills, humor, perspective-taking, empathy, etc.) with a controlled follow-up opportunity to practice the skill of interest (e.g., Laugeson et al. 2012; Ozonoff and Miller 1995; Webb et al. 2004; White et al. 2010). Opportunities for experiential learning remain relatively limited and are commonly relegated to social homework assignments in school or community settings (outside of the structured intervention context). While this instructional format has yielded very promising evidence of therapeutic effect, it does not currently offer embedded experiential components that might address other key barriers, such as limited motivation or peer acceptance challenges, which may prevent or limit access to practice opportunities within natural social contexts. In other words, adolescents may not be able to practice a newly learned social skill with a peer group that actively rejects or ignores them.

There may be unexplored benefits of a social instruction model that places equal emphasis on opportunities for dynamic, natural interactions within a peer group (experiential learning) along with more commonly used didactic learning approaches. This "learn by doing" augmentation 
may be crucial to the development of social competency, as it may expose participants to sufficient opportunities to both (a) feel included and accepted by a group of peers and (b) use this forum to become fully immersed in a dynamic, reflective learning process (i.e., experience both success and failure within a forgiving social environment, process these experiences, further develop one's abstract conceptualization of social understanding, and return to this context to experiment with more effective strategies). This therapeutic arrangement provides a seamless generalization opportunity while also creating unique opportunities to embed learning strategies that promote self-awareness and reflection into a social learning program. This may be especially important given the concerns about sustainability and generalizability in autism intervention efforts, which may be linked to the limited metacognitive capacities of individuals with ASD (Grainger et al. 2014; Williams et al. 2009). Specifically, these individuals may struggle with generalized application of social principles due to limited self-awareness and reflection skills.

As a promising method for increasing self-awareness and reflection, self-management is a relatively discrete intervention technology that can be easily embedded within an experiential context. These methods have received considerable research attention for transferring monitoring responsibilities to the actual person engaging a desired target skill (see Lee et al. 2007 for a review and meta-analysis). Within this context, individuals are taught to track their own behavior in an effort to promote awareness and internalized skill acquisition. These methods have been used in previous investigations to specifically target social skills (e.g., Doggett et al. 2013; Koegel et al. 1992; Newman and Ten Eyck 2005) along with self-regulation and mindfulness (Carr et al. 2014). Self-management fosters a sense of intentionality in one's actions and allows for guided experimentation with a new set of social interaction strategies. In addition to promoting opportunities to engage in reflective practice, another advantage of self-management is that adolescents participating in a group intervention can self-manage different social skills-each reflective of a slightly different vulnerability profile. In other words, it is possible to individualize an aspect of the intervention package even within the context of a group-based program. This promising monitoring strategy is explored as an experiential technique within the context of the current investigation.

The goal of the current study was to evaluate a hybrid socialization intervention approach that combines experiential and didactic components into a single multi-component treatment model. Specifically, a program description and preliminary outcomes will be provided for the Social Tools And Rules for Teens (START) program, a comprehensive social skills intervention for adolescents with ASD.

\section{Method}

This project received Institutional Review Board (IRB) approval and was conducted at a North American university.

\section{Participants}

A total of six adolescents participated in the initial investigation of the START program. Participants were adolescents aged 12-17 with an existing diagnosis of ASD meeting current DSM-5 criteria. Inclusion criteria also included (a) use of full sentence phrases to communicate (fluent language use), (b) a verbal IQ equal to or greater than 70, and (c) an ASD diagnosis confirmed by meeting cut-offs designated by the Autism Diagnostic Observation Schedule, Second Edition (Lord et al. 2012), Autism Diagnostic Interview, Revised (Rutter et al. 2003), and the Social Responsiveness Scale, Second Edition (Constantino and Gruber 2005).

Participants were recruited from several sources, including communications with local high schools, referrals from community organizations, word of mouth, and responses from online research announcements. All potential participants were scheduled for intake appointments to ensure that they met all inclusion criteria and complete pre-intervention measures. A summary of participant demographic information is provided in Table 1.

\section{Design}

For this preliminary investigation, a combination of a clinical case series and a multiple baseline design across participants and behaviors was employed to understand the social improvement trajectories of participants as they progressed through the START program. Initially, the participants completed all dependent measures during two pre-intervention sessions spaced 5 weeks apart to assess for the stability of social measures in the absence of any social intervention efforts. Following the onset of intervention, they were reassessed with all measures after completion of $5,10,15$, and 20 (final) session time points during separate progress meetings.

\section{Procedure}

\section{Social Facilitator Training}

High-achieving college students were recruited from university undergraduate psychology courses to serve as social facilitators for the START program. These volunteers received an initial 10-h training on basic group facilitation 


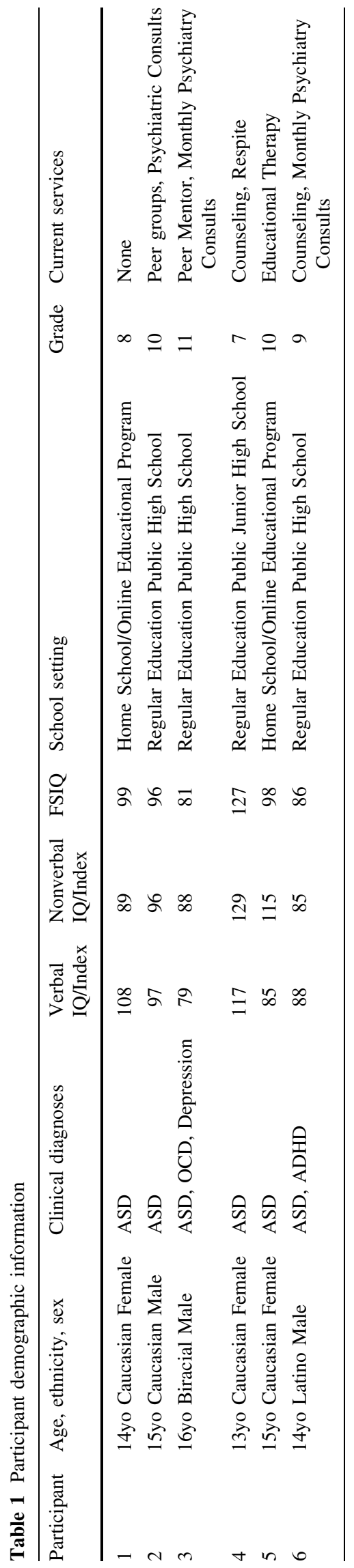

techniques, covering basic group facilitation skills, methods for fostering rapport, and exposure to practice group sessions. The social facilitators also participated in weekly 1-h supervision meetings for ongoing clinical training purposes. An advanced clinical psychology doctoral student and a licensed clinical psychologist jointly conducted all training and supervision sessions.

\section{Pre-Intervention Sessions}

All participants completed an initial 90-min intake session, which consisted of obtaining consent/assent from parents and adolescents, obtaining basic demographic information, and completing all required measures. After a five-week waiting period, participants returned to re-complete these measures in a second pre-intervention session. Trained research assistants conducted all intakes and subsequent progress meetings.

\section{Target Skill Selection and Self-Management}

During the initial pre-intervention session, an assessment of individual social vulnerabilities was conducted. Participants were provided with a list of 12 common social skill difficulties/vulnerabilities with the option to write in additional concerns that were not listed. This list was generated internally by the research team and included commonly observed social skill deficits among the clinical population: asking relevant (on-topic) questions, making relevant comments, increasing conversational bids, limiting conversational contributions (over-sharing), greeting others, ending conversations appropriately, using voice qualities (volume, rate, intonation), making eye contact, directing appropriate facial expressions, expressing empathy, choosing appropriate (positive) topics of conversation, using humor, and complimenting others. Based on a rank order of specific social skill difficulties completed separately by each adolescent, their parent, and an intake clinician, consensus was reached on an individual social skill to serve as the initial focus of self-management. The primary objective was to directly target the social skill deficit that was identified as having the largest negative impact on each adolescent's level of social success. In this preliminary investigation, a total of four different skill targets were targeted among the six participants.

During the second pre-intervention meeting, the assigned facilitator reintroduced the selected social skill to the adolescent and they jointly discussed the value of that particular skill in the process of forming and maintaining relationships. The skill was operationally defined for the participant, modeled by the social facilitator, and then practiced in a brief conversational exchange. After the participant verbally expressed a strong understanding of 
the target social skill and successfully demonstrated accurate self-management in conversation (i.e. using a small digital tally counter to record using the skill appropriately), they were subsequently encouraged to self-manage their use of this skill during each START group session. Individual goals were reevaluated every 5 weeks and new skills were introduced as participants either (a) demonstrated adequate mastery of a previous target skill or (b) exhibited a more significant challenge in another skill domain that was identified as a greater source of social difficulty.

\section{START Program Sessions}

All of the adolescents began participation in the START program immediately following completion of their second set of pre-intervention measures. The 2-h weekly program consisted of the following components: an individual therapeutic check-in session, a group unstructured socialization time, a structured group activity, a group discussion and practice of a social skill topic, and an individual checkout session with parent involvement. All participants and 3-5 social facilitators took part in each group. The structure of each session is depicted in Fig. 1.

Check-In Session. The 5-min individual check-in session was run by an individually assigned social facilitator and took place in a small clinic room. Within an experiential learning model, these sessions provided an opportunity for the participants to reflect on their social experiences and social homework objectives of the previous week. To concretize this process, the participants first rated their perceived level of success in using their individual target skill and their general level of social comfort over the past week using a 5-point Likert scale. These ratings were then used to facilitate private discussion and reflection between participants and their facilitators on their perceived social difficulties and successes. As a method to encourage participants to engage in abstract conceptualization of the previous week's social topic, participants were encouraged to focus on a particularly salient social event and connect their use of specific skills to the ultimate outcome of the interaction. The check-in sessions were also used to prime the participant with a brief description of the session activities and practice self-management in a brief conversation with the clinician. Finally, participants were reminded to (a) monitor social group reactions to their use of their target skill to solidify their understanding of why certain strategies make them a more desirable social partner and (b) engage in active experimentation during the group (e.g. make different types of social inquiries or tell someone a different personal anecdote). After completing the individual check-in sessions, all participants were brought together to start the group phases.

Unstructured Socialization Phase. The first $20 \mathrm{~min}$ of the group consisted of unstructured socialization time. When mapped onto the experiential learning model, this time period served as the concrete social experience to facilitate reflective observation. This unstructured time was allowed to unfold without a predetermined agenda and was intended to create a natural, comfortable social context in which to engage in both reflective observation and active experimentation. Topics were introduced by the participants and often included video games, favorite foods and places to eat, school and current events, vacation and weekend plans, and memorable personal experiences. Food and refreshments were provided during each group to aid in the creation of a casual, club-like atmosphere. While conversing with one another, the participants and social facilitators simultaneously tracked their use of individual target skills. Social facilitators also participated in this process to ensure that every group member adhered to identical program expectations and stigma was minimized. It was explained that everyone can improve the intentionality of their social actions, and the social facilitators modeled this assertion by tracking their own use of a personally identified skill of interest (e.g. questions, compliments, positive statements, expressions of empathy, etc.).

Group Activity Phase. After approximately $20 \mathrm{~min}$, the group transitioned into a structured social activity. These activities varied each week, but generally resembled commonly used team-building activities and party games. This phase was intended to foster sharing of personal information, encourage learning about peer interests, increase comfort in the group context, and promote cooperation and teamwork in a highly structured context. Examples of activities included Social Bingo, Apples to Apples, Bowl of Nouns, and Headbands. Activities served as additional experiences for reflective observation and social experimentation. They were selected to be highly enjoyable and intrinsically motivating to increase the engagement of the group participants. Collateral benefits included opportunities to work on effective communication, compromise, teamwork, and sportsmanship skills.
Fig. 1 START program session timeline

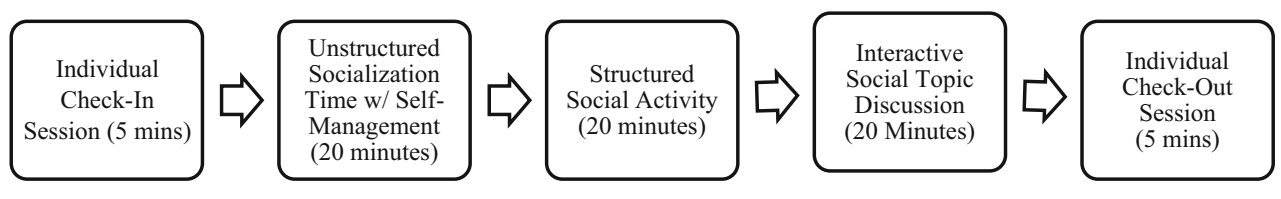


Topic Discussion and Practice Phase. After the structured activity phase, individuals were asked to share their reflections on the previous week's topic that were originally discussed during the check-in session. Common themes and challenges were identified and discussed as a group to promote deeper understanding of each social concept. The social facilitators then introduced the week's social skill topic, which was discussed for the remaining time of the group session. After a brief introduction of the target skill, the topic was then modeled by the social facilitators in a series of two brief contrasting role-playsone "bad" example demonstrating poor implementation of the skill and a follow-up "good" example depicting proper use of that particular skill. Social facilitators then discussed pre-determined topic summary items and illustrated them by describing relevant personal experiences. The adolescent participants were then encouraged to contribute to the topic-discussing their experiences related to that topic and providing relevant suggestions regarding the successful use of a particular social skill. Finally, for the last $5 \mathrm{~min}$ of the group, all participants practiced the related skill with a partner. A manualized curriculum of key points and sample stories/scripts were used to structure and guide these discussions. This portion of the group was intended to promote joint understanding of a social skills topic and provide opportunities to both observe and practice the skill. Social skills topics covered included: making introductions, maintaining a conversation, respectfully disagreeing, and group interactions. A complete list of the topic curriculum is depicted in Table 2.

Check-Out Session. Finally, a 5-min individual checkout session was conducted with each participant, one parent, and a social facilitator. Participants rated their level of comfort (a) using their identified target skill and (b) interacting with the group using separate 1-5 Likert scales. They were then asked to use these ratings as a means to reflect back on their experience and form hypotheses about why they felt that the group went positively or negatively. This process was intended to help the participants review their interactions in an intentional, systematic way to ensure that they could fully benefit from the experiential learning process. Each participant was then given personalized feedback about aspects of their group participation that the facilitator felt was exemplary, along with areas that may have warranted improvement. This process was intended to model the abstract conceptualization process by connecting specific participant behaviors to reactions from their peer group. This discussion was intended to establish general guiding concepts for future socialization experiences. For example, the facilitator might point out how a participant's harsh criticism caused a peer to become visibly upset in the group, or how a fellow peer smiled when the participant used a compliment appropriately. The participants were then encouraged to discuss the group social skills topic with their parents to foster mutual understanding and continued use of the skill in their home
Table 2 START weekly group discussion topics

\begin{tabular}{ll}
\hline Week & Topic \\
\hline 1 & Greeting others/making initial introductions \\
2 & Using questions in conversation \\
3 & Using comments in conversation \\
4 & Showing interest—attention, eye contact, facial expressions \\
5 & Choosing appropriate topics for conversations \\
6 & Making and keeping friends \\
7 & Changing topics/ending conversations/saying goodbye \\
8 & Reducing anxiety/being comfortable during social exchanges \\
9 & Expressing empathy \\
10 & Complimenting others \\
11 & Making a good impression/giving social feedback \\
12 & Receiving social feedback \\
13 & Respectfully disagreeing with others \\
14 & Demonstrating good sportsmanship/being a good winner and loser \\
15 & Working in a group/being a good team member/leader \\
16 & Using appropriate humor and understanding/using sarcasm \\
17 & Having social courage/joining a new group of peers \\
18 & Using social media \\
19 & Hosting others at your home/being a good guest at someone's home \\
20 & Summary of group topics and conclusion \\
\hline
\end{tabular}


environment. As a final step, the social facilitator, participant, and parent(s) jointly established two social skills homework goals to work on during the following weekone based on the individual's self-management goal and one based on the weekly topic discussed in group. Takehome sheets were provided to allow participants and parents to track their completion of the homework objectives each week. This process ensured that participants continued to seek out additional experiential learning opportunities in their natural social settings so that they could process them during the next session.

\section{Fidelity of Implementation}

While sessions were not videotaped, a fidelity checklist was completed during each group session to monitor adherence to the established intervention protocol. Session fidelity fell consistently above $95 \%$. As an additional treatment integrity safeguard, project investigators also sat in on random group sessions to observe.

\section{Data Collection}

In addition to the two pre-intervention sessions, social skills data were also collected during progress meeting sessions held every 5 weeks between regularly scheduled group meetings (i.e. between the 5 th and 6 th sessions, 10th and 11th sessions, 15 th and 16th session, and after the final 20th session). Participants and parents completed all survey and conversational probe measures described below.

\section{Dependent Measures}

\section{Parent and Adolescent Social Survey Measures}

A variety of self- and parent-reported survey instruments were administered to assess changes to social competence:

Social Skills Improvement System Rating Scales (SSIS$R S)$. The SSIS-RS is a 75-83 item revised version of a widely-used rating scale measuring several aspects of social skills, including Communication, Cooperation, Assertion, Responsibility, Empathy, Engagement, and SelfControl (Gresham and Elliott 2008). Internal consistency alpha reliability coefficients for the parent and self-report forms are reported to be in the mid to upper $.90 \mathrm{~s}$, with moderate to high correlations to corresponding social and behavioral scales on the Behavior Assessment System for Children, Second Edition and the Vineland Adaptive Behavior Scales, Second Edition. Both parent and adolescent-report surveys were completed during each progress meeting.

Social Responsiveness Scale, Second Edition (SRS-2). The SRS-2 a 65 item rating scale that covers various dimensions of interpersonal behavior, communication, and stereotypic behavior associated with ASD (Constantino and Gruber 2005). Score reductions are associated with a decrease in the severity of ASD symptoms. Internal consistency alpha reliability coefficients for the parent forms were reported to be above 0.90 and strong correlations were reported ( $\mathrm{r}=0.52-0.74)$ with subscales of the ADI-R.

Social Motivation \& Competencies Scale (SMCS). The SMCS is unpublished rating scale that was developed by the current researchers for use in this study. Separate parent and adolescent self-report versions were developed that contained identical item content. Items pertaining to comfort in social interaction, conversation skill use, empathy, friendships, appropriate behavior, social contact, and social interest are rated on 1-5 Likert scales. See "Appendix 1" to review the SMCS survey items.

\section{Dynamic Conversation Probe Data}

This investigation also employed the use of live conversations to assess dynamic social skill changes on a variety of individualized social target skills. During the two preintervention and four intervention progress meetings, participants engaged in two separate 5-min (600 s) "get to know you" conversations with both an unfamiliar male peer and an unfamiliar female peer. These peers were unaffiliated with the research project and were naïve to the project aims or participant's social disability status. Dynamic social data were obtained through the systematic coding of these video-recorded conversations, and data from both conversations recorded on the same day were combined to create a mean score for that progress meeting. Trained research assistants that were naïve to the hypotheses of the study and treatment aims coded all conversation videos in random order. Individualized target skill measures fell into four categories:

Increasing Social Inquiries. Question asking has been described in the literature as a crucial social skill (Doggett et al. 2013; Palmen et al. 2008; Weiss and Harris 2001). A frequency count of social inquiries made in the video clips was conducted for both the participant and the conversational partner. A social inquiry was defined as verbal question that was clearly intended to elicit a verbal response from a conversational partner. Both number of social inquiries and the percentage of the total inquiries made were calculated. The ultimate objective of this target skill was to increase participant social inquiries so that a roughly equal number of questions $(50 \%)$ was exchanged between them and their conversational partners, which would be an indication of a balanced, reciprocal conversational exchange. Inter-rater reliability for social inquiries was calculated for approximately $33 \%$ of videos and resulted in a mean of $88 \%$ agreement (range of 82-96 \%). 
Decreasing Negative Statements. Individuals with ASD often have limited understanding of socially appropriate topics of conversation and offer overly honest opinions about subject matter without filtering their messages (Landa 2000). Several individuals in this study struggled to engage in primarily positive topics of conversation. Therefore, goals were set to increase the number of positive and neutral statements while simultaneously decreasing the occurrence of negative statements. A negative statement was defined as a critical judgment or unfavorable comment about oneself or another person, topic, or event. Twenty-second intervals were coded by raters as focusing primarily on (a) negative or (b) positive/neutral subjective content. A percentage was then calculated to determine the ratio of intervals in the conversation that were dominated by negative comments. Inter-rater reliability for negative statements yielded a mean of $90 \%$ agreement (range of $81-100 \%)$.

Increasing Verbal Contributions. The successful use of social conversational bids is associated with higher levels of peer acceptance (Burleson et al. 1986), while interpersonally reserved individuals generally possess a lower level of sociometric status (Newcomb et al. 1993). Participant 5 was noted to speak very infrequently during pre-intervention conversations and was encouraged to increase the frequency of verbal contributions. During five-second intervals, raters coded whether or not the participant made a verbal contribution of more than two words. This cut-off ensured that a participant who habitually provided only minimal verbal responses to questions (e.g. responding "yes" or "not really") was not coded as providing appropriate verbal contributions to a conversation. A percentage was then calculated to determine the total percentage of time participants were speaking during each 5-min clip.

Decreasing Verbal Contributions. Alternatively, an excessive, pedantic speaking style is also observed in select subgroups of individuals with ASD (Ghaziuddin and Gerstein 1996), particularly during discussions of highly preferred thematic content (Elder et al. 2006; Nadig et al. 2010). Participant 4 was encouraged to work on limiting her excessive level of verbal information in order to allow her conversational partners more opportunities to participate in discussions. An identical verbal contribution coding definition (described above) was implemented using fivesecond intervals. Inter-rater reliability for both verbal contribution categories yielded a mean of $92 \%$ agreement (range of $82-100 \%$ ).

\section{Social Validity Ratings}

Parents and participants were both asked to provide ratings to provide information about the acceptability of the START program. Specifically, they were asked to provide separate ratings on a 0-10 Likert scale on both (a) enjoyment of the adolescent's time in the group and (b) the extent to which the adolescent's social skills/competence improved as a result of participation. The specific questions provided to participant and parent were as follows:

On a scale from 0 to 10 , how much did you enjoy (for parents: do you think your child enjoyed) being a part of the social club?

On a scale from 0 to 10 , how much did your (for parent: your child's) social skills/competence improve through participation in the club?

\section{Results}

\section{Parent and Adolescent Social Survey Measures}

Survey data and associated effect sizes for all participants are summarized in Table 2 .

\section{$S S I S-R S$}

Parent-reported SSIS-RS Social Skills standard scores were noted to yield consistently positive score increases (mean of 5.3, range of 2.25-8.25) when comparing the mean of the final two intervention progress meetings to the mean of the two pre-intervention scores over the course of the project, with four exceeding the SSIS-RS's Standard Error of Measurement (SEM = 3).

For the adolescent self-report SSIS-RS Social Skills, a mean comparison from the final two progress meeting scores to both pre-intervention scores indicated that four participants $(1,2,4,5)$ endorsed general gains to their Social Skills standard score (exceeding the measure's SEM) while two $(2,6)$ endorsed a decrease in total score.

\section{SRS-2}

When comparing pre-intervention and intervention means for the SRS-2, five participants $(1,2,3,5,6)$ experienced a reduction in their total score that exceeded the SRS-2's SEM of 2.2, which is indicative of the desired decrease in their endorsement of autism-related symptoms. The mean change in SRS-2 score was -4.3 (range of -11 to 3 ). One participant (6) experienced a negligible change, and one (2) experienced an increase in score.

\section{SMCS}

For the parent-reported SMCS scores, a comparison of the mean of participant pre-intervention scores to the final 
intervention progress meeting scores were indicative of social increases (mean of 9.1 point increase with a range of 3.0-34.0 points).

A comparison of the pre-intervention mean to the progress meeting scores demonstrated Four participants (1, 3, $4,5)$ endorsed gains in their adolescent self-report SMCS total scores, while two $(2,6)$ experienced a decrease in their mean score. The mean change in score across all participants was 10.7 (range of -10.5 to 28 ).

\section{Dynamic Conversation Probe Data}

Dynamic conversation probe data is summarized below and is generally reflective of improvements to individualized target social skills (with medium to large effect sizes). Results are described for each individual participant below (Table 3).

\section{Participant 1: Increase Social Inquiries and Decrease Negative Statements}

Participant 1 exhibited consistently low levels of question asking prior to beginning the intervention, asking a mean of 5 questions (range of 4-9) during the 10-min pre-intervention probes, representing a mean of $17.8 \%$ (range of 11.6-24.0\%) of the total questions asked during her conversations. This skill was actively targeted in the first 5 weeks of the START program, and Participant 1

Table 3 Parent and adolescent-report social survey scores

\begin{tabular}{|c|c|c|c|c|c|c|c|c|c|c|c|c|c|}
\hline \multirow{4}{*}{$\begin{array}{l}\text { Survey measure } \\
\\
\text { SSIS-RS_parent rating } \\
\text { social skills standard } \\
\text { score }\end{array}$} & \multirow{2}{*}{$\begin{array}{l}\text { Adol } \\
1\end{array}$} & \multirow{2}{*}{$\begin{array}{l}\text { Pre } \\
1 \\
47\end{array}$} & \multirow{2}{*}{$\begin{array}{l}\text { Pre } \\
2 \\
58\end{array}$} & \multicolumn{2}{|c|}{$\begin{array}{l}\text { Pre- } \\
\text { intervention } \\
\text { mean }(\mathrm{SD})\end{array}$} & \multirow{2}{*}{$\begin{array}{l}\text { Week } 5 \\
\text { Progress } \\
54\end{array}$} & \multirow{2}{*}{$\begin{array}{l}\text { Week } \\
10 \\
\text { Progress } \\
65\end{array}$} & \multirow{2}{*}{$\begin{array}{l}\text { Week } \\
15 \\
\text { Progress } \\
62\end{array}$} & \multirow{2}{*}{$\begin{array}{l}\text { Week } \\
20 \\
\text { Progress } \\
62\end{array}$} & \multicolumn{2}{|c|}{$\begin{array}{l}\text { Intervention } \\
\text { mean (SD) }\end{array}$} & \multirow{2}{*}{$\begin{array}{r}\begin{array}{l}\Delta \\
\text { Mean } \\
\text { score }\end{array} \\
9.5\end{array}$} & \multirow{2}{*}{$\begin{array}{r}\begin{array}{l}\text { Effect } \\
\text { size }\end{array} \\
2.44\end{array}$} \\
\hline & & & & 52.5 & $(7.78)$ & & & & & 62 & $(0.00)$ & & \\
\hline & 2 & 83 & 78 & 80.5 & $(3.54)$ & 80 & 84 & 93 & 85 & 89 & $(5.66)$ & 8.5 & 1.94 \\
\hline & 3 & 89 & 92 & 90.5 & $(2.12)$ & 95 & 101 & 83 & 105 & 94 & (15.56) & 3.5 & 0.32 \\
\hline & 4 & 84 & 84 & 84 & $(0.00)$ & 84 & 95 & 92 & 80 & 86 & $(8.49)$ & 2 & 0.33 \\
\hline & 5 & 81 & 67 & 74 & (9.90) & 74 & 78 & 77 & 84 & 80.5 & $(4.95)$ & 6.5 & 1.07 \\
\hline & 6 & 76 & 76 & 76 & $(0.00)$ & 81 & 76 & 81 & 75 & 78 & $(4.24)$ & 2 & 0.67 \\
\hline \multirow{6}{*}{$\begin{array}{l}\text { SSIS-RS_-adolescent } \\
\text { rating social skills } \\
\text { standard score }\end{array}$} & 1 & 86 & 84 & 85 & $(1.41)$ & 103 & 106 & 102 & 103 & 102.5 & $(0.71)$ & 17.5 & 20.21 \\
\hline & 2 & 77 & 91 & 84 & $(9.90)$ & 79 & 82 & 89 & 86 & 87.5 & $(2.12)$ & 3.5 & 0.68 \\
\hline & 3 & 100 & 100 & 100 & $(0.00)$ & 98 & 95 & 92 & 85 & 88.5 & $(4.95)$ & -11.5 & -3.29 \\
\hline & 4 & 115 & 115 & 115 & $(0.00)$ & 127 & 127 & 128 & 128 & 128 & $(0.00)$ & 13.5 & 27.00 \\
\hline & 5 & 94 & 109 & 101.5 & (10.61) & 119 & 121 & 123 & 124 & 123.5 & $(0.71)$ & 22 & 4.13 \\
\hline & 6 & 78 & 68 & 73 & (7.07) & 89 & 72 & 67 & 65 & 66 & $(1.41)$ & -7 & -1.91 \\
\hline \multirow{6}{*}{$\begin{array}{l}\text { SRS_parent total } \\
\text { standard score (Lower } \\
\text { scores indicate } \\
\text { improvement) }\end{array}$} & 1 & 90 & 90 & 90 & $(0.00)$ & 90 & 90 & 77 & 88 & 82.5 & (7.78) & -7.5 & -1.36 \\
\hline & 2 & 74 & 73 & 73.5 & $(0.71)$ & 70 & 69 & 67 & 70 & 68.5 & $(2.12)$ & -5 & -3.24 \\
\hline & 3 & 71 & 78 & 74.5 & $(4.95)$ & 69 & 61 & 85 & 57 & 71 & (19.80) & -3.5 & -0.25 \\
\hline & 4 & 65 & 65 & 65 & $(0.00)$ & 64 & 68 & 68 & 68 & 68 & $(0.00)$ & 3 & -* \\
\hline & 5 & 79 & 81 & 80 & $(1.41)$ & 70 & 72 & 72 & 66 & 69 & $(4.24)$ & -11 & -3.57 \\
\hline & 6 & 71 & 70 & 70.5 & $(0.71)$ & 70 & 74 & 68 & 69 & 68.5 & $(0.71)$ & -2 & -3.27 \\
\hline \multirow{6}{*}{$\begin{array}{l}\text { SMCS_-parent rating } \\
\text { total raw score }\end{array}$} & 1 & 48 & 51 & 49.5 & $(2.12)$ & 65 & 77 & 83 & 109 & 96 & (18.38) & 12.5 & 11.79 \\
\hline & 2 & 69 & 77 & 73 & $(5.66)$ & 73 & 78 & 79 & 76 & 77.5 & $(2.12)$ & 16 & 3.27 \\
\hline & 3 & 92 & 87 & 89.5 & $(3.54)$ & 94 & 99 & 70 & 107 & 88.5 & $(26.16)$ & 4.5 & 0.40 \\
\hline & 4 & 81 & 81 & 81 & $(0.00)$ & 85 & 90 & 96 & 92 & 94 & $(2.83)$ & 5 & 0.83 \\
\hline & 5 & 67 & 65 & 66 & $(1.41)$ & 76 & 80 & 81 & 90 & 85.5 & $(6.36)$ & 14.5 & 4.06 \\
\hline & 6 & 79 & 73 & 76 & $(4.24)$ & 85 & 78 & 84 & 74 & 79 & (7.07) & 2 & 0.54 \\
\hline \multirow{6}{*}{$\begin{array}{l}\text { SMCS_-adolescent } \\
\text { rating total raw score }\end{array}$} & 1 & 97 & 95 & 96 & $(1.41)$ & 116 & 118 & 115 & 119 & 117 & $(2.83)$ & 21 & 13.14 \\
\hline & 2 & 84 & 81 & 82.5 & $(2.12)$ & 63 & 68 & 81 & 81 & 81 & $(0.00)$ & -1.5 & -1.23 \\
\hline & 3 & 102 & 102 & 102 & $(0.00)$ & 101 & 100 & 151 & 104 & 127.5 & (33.23) & 25.5 & 0.59 \\
\hline & 4 & 120 & 120 & 120 & $(0.00)$ & 128 & 128 & 128 & 127 & 127.5 & $(0.71)$ & 7.5 & 18.98 \\
\hline & 5 & 83 & 89 & 86 & $(4.24)$ & 105 & 118 & 109 & 119 & 114 & (7.07) & 28 & 4.57 \\
\hline & 6 & 107 & 105 & 106 & $(1.41)$ & 99 & 105 & 82 & 109 & 95.5 & (19.09) & -10.5 & -0.74 \\
\hline
\end{tabular}

* Could not be calculated due to baseline and intervention SD of 0.00 
increased her number of social inquiries to 10 and asked $48.7 \%$ of the total questions in her conversation probes. After her target skill changed and social inquiries were no longer her active target (reflected in progress meetings $2-4)$, she continued to ask a mean of $39.1 \%$ of the total questions asked (range of 20.0-46.9\%), consisting of a mean of 12 questions per conversation (range of 8-15), although a decreasing trend was noted. The effect size for increases in her social inquiries overall was large $(d=1.88)$.

Once she demonstrated initial proficiency with use of social inquiries at progress meeting 1, Participant 1's goal was changed to address the amount of negative statements she made. She was asked to decrease her negative statements by focusing on increasing her use of positive and neutral statements. During the baseline phase for this new target behavior (which included both pre-intervention sessions and the first progress meeting), Participant 1 was found to discuss negative topics a mean of $30.4 \%$ of conversational intervals (range of 24.0-40.5\%). Her negative statements initially remained high at $35.0 \%$ the first five weeks of actively targeting this behavior and subsequently decreased at 10 and 15 weeks of intervention to a mean of $17.3 \%$ (range of 8.5-11.0\%). The effect size for negative statements was also large, $\mathrm{d}=-1.07$ (with the negative value indicative of the desired reduction in negative statements). Participant 1's data is depicted in Fig. 2.
Participant 2: Increase Social Inquiries and Decrease Negative Statements

Participant 2 also exhibited low initial levels of social inquiries (mean of 2.3, range of 1-4), constituting a mean of $7.7 \%$ (range of 4.6-10.7\%) of total questions asked per conversation. After targeting this skill for the first five sessions prior to progress meeting 1 , his percentage of questions asked increased to $18.5 \%$ (5 total questions per conversation). At this timepoint, Participant 2's level of negativity was determined to be having a greater impact on his social success than his number of social inquiries. After this change to focus on negative statements, Participant 2's number and percentage of social inquiries continued to improve during the post-target phase (progress meetings 2-4), increasing to a mean of $26.4 \%$ (range of 15.7-44.4\%) with a mean of 5.5 total questions (range of 3-10). There was a notable increasing trend in the data, even though making social inquiries was no longer the active target skill. The effect size for Participant 2's improvement in making social inquiries was large, $d=1.51$.

Despite notable reliance on negative conversational strategies during group, Participant 2 only engaged in negative statements for a mean of $4.8 \%$ (range of 3.0-6.0\%) of conversational intervals while conversing with novel social partners (possibly due to his need to "be polite" with unfamiliar individuals). During the active target phase (progress
Fig. 2 Participant 1's dynamic conversation target social goals: increase social inquiries and decrease negative statements

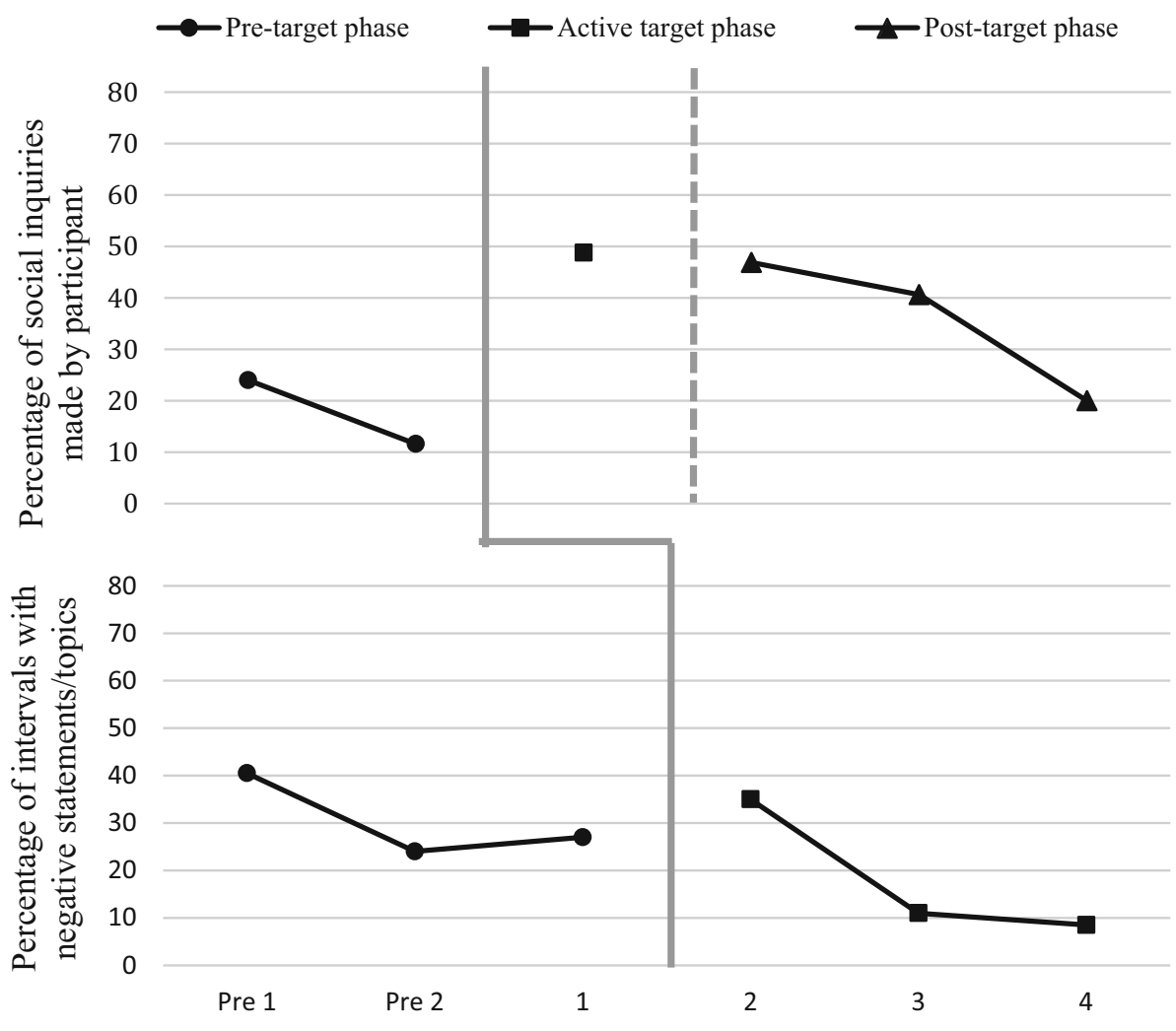


Fig. 3 Participant 2's dynamic conversation target social goals: increase social inquiries and decrease negative statements

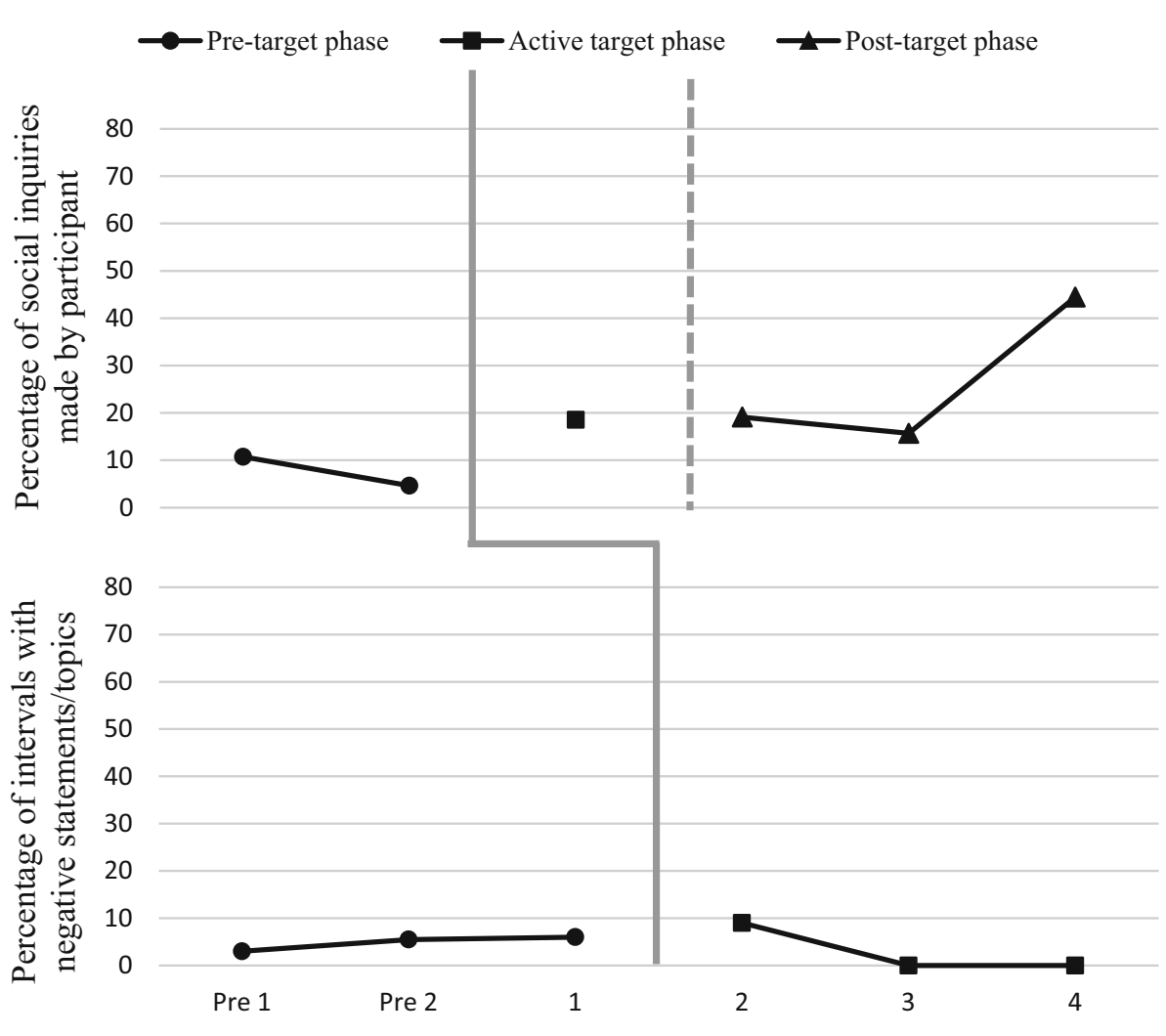

meetings 2-4), his percentage of negative statements initially increased to $9.0 \%$ but then decreased to $0 \%$ for the remaining 2 progess meetings (overall mean of $3.0 \%$ ). The effect size for Participant 2's decrease in negative statements was indicative of a medium effect $(d=-0.48)$. Participant 2's data is depicted in Fig. 3.

\section{Participant 3: Decrease Negative Statements}

Participant 3's individual target focused on decreasing reliance on negative statements throughout the entire duration of the 20-week intervention. Prior to intervention, his percent of conversational intervals with negative statements ranged from 3.0 to $15.5 \%$ (a mean of $9.3 \%$ ) and during the active target phase ranged from 5 to $11.5 \%$ (a mean of $7.5 \%$ ). The calculated effect size is indicative of a medium effect size $(d=-0.41)$, although a visual inspection of the data reveals a significant overlap in the pre-intervention and intervention data and lack of a clear treatment effect. Participant 3's data is depicted in Fig. 4.

\section{Participant 4. Increase Social Inquiries and Decrease Verbal Contributions}

Due to a participant unavailability due to a personal obligation, Participant 4 was only able to complete a single pre-intervention session for conversation probes. At that time, the percent of her social inquiries was $27 \%$ (7.5
Fig. 4 Participant 3's dynamic conversation target social goal: decrease negative statements

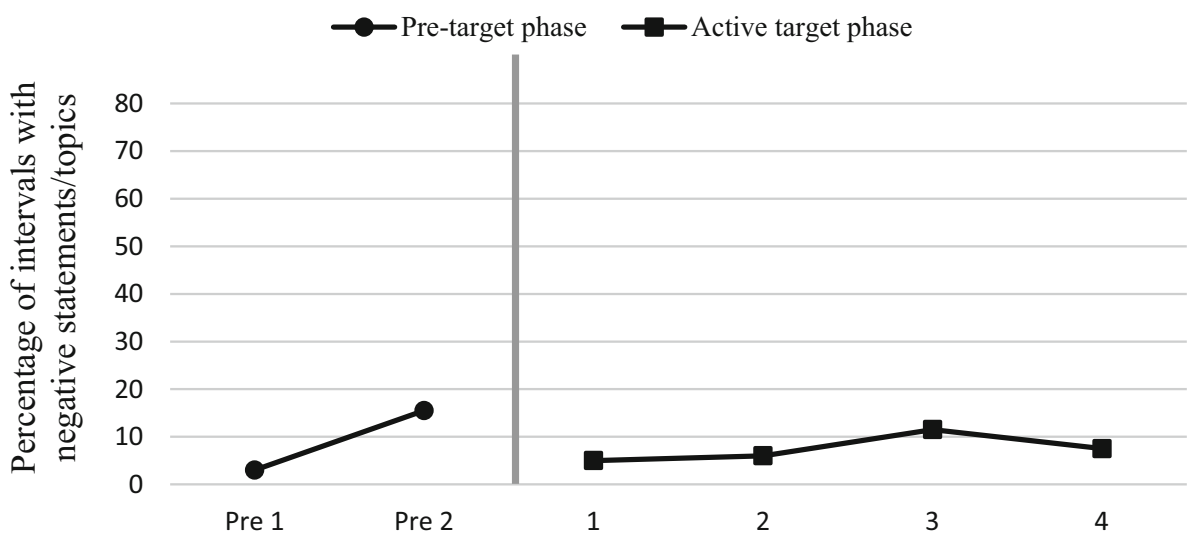


questions per conversation). During her active target skill phase (following the first five sessions and measured at progress meeting 1) the percentage increased to a mean of $40.0 \%$ of total social inquiries made in the conversation (16.5 questions). During the post-target phase when social inquiries were no longer the focus of self-management (progress meetings 2-4), Participant 4's percentage of total social inquiries remained at a mean of $32.3 \%$ (range of 27-35\%) with a total mean of 10.8 questions (range of 5-15). This sustained improvement was indicative of a large effect $(d=1.54)$.

Participant 4's target objective shifted to focus on reducing her verbal contributions for sessions 6-20 (and assessed during progress meetings 2-4). During the pretarget phase, her verbal contributions made up a mean of $75 \%$ of conversational intervals (range of 71-79\%). During the active target phase (progress meetings 2-4), she reduced her verbal contributions to a mean of $61 \%$ (range of 51-70\%), with a notable decreasing trend in her data. This change was indicative of a large effect $(d=-1.74)$. Participant 4's data is depicted in Fig. 5.

\section{Participant 5: Increase Social Inquiries and Increase Verbal Contributions}

Participant 5 did not make any social inquiries (0) during her pre-intervention conversation probes. When this skill was actively targeted (progress meetings 1-2), the percent of social inquiries made increased to a mean of $31.0 \%$ of the total questions asked (range of 27.8-34.2\%). She asked a mean of 5.8 questions per conversation (range of 3-9). During the post-target phase (progress meetings 3-4), she made a total of $26.6 \%$ of the total social inquiries in the conversation(range of 14.3-38.9\%), asking a mean of 5.5 questions (range of 4-7). The increase from pre-intervention is indicative of a large effect size $(d=3.30)$.

After targeting social inquiries, Participant 5's target goal shifted to increasing her verbal contributions for the final two progress meetings. During the pre-target phase she spoke during a mean of $43.1 \%$ of conversational intervals (range of 36.0-51.0\%). When verbal contributions became the active treatment target, Participant 5's contributions increased to a mean of $62.5 \%$ (range of 57.5-67.5\%) for progress meetings 3 and 4. This change was indicative of a large effect size $(d=2.90)$. Participant 5's data is depicted in Fig. 6.

\section{Participant 6: Increase Social Inquiries and Decrease Negative Statements}

Participant 6 contributed minimally to the total social inquiries that were made during his pre-intervention conversation probes, making up a mean of $1 \%$ of total questions asked (range of $0-1.6 \%$ ). He made a total mean of
Fig. 5 Participant 4's dynamic conversation target social goal: increase social inquiries and decrease verbal contributions

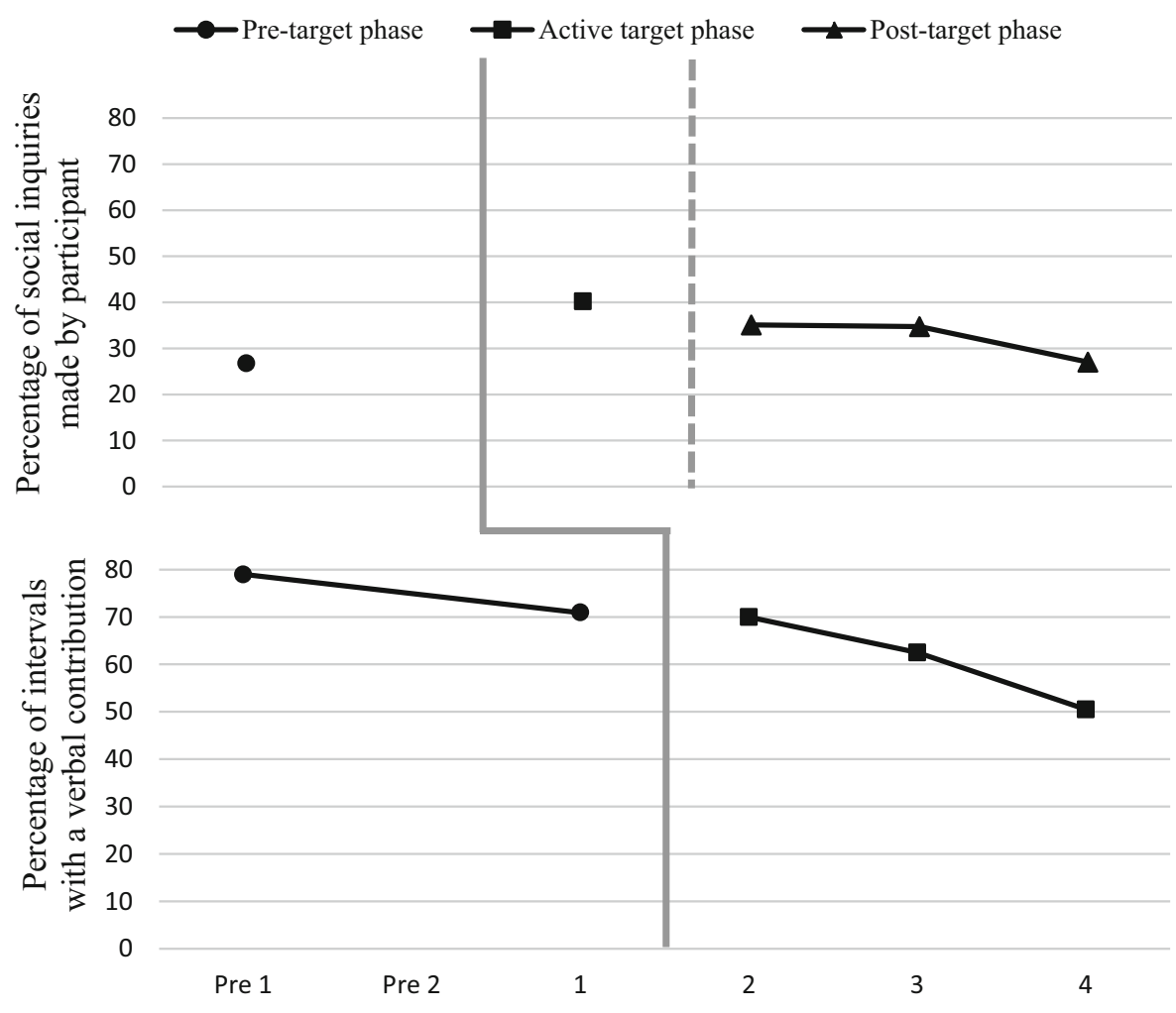


Fig. 6 Participant 5's dynamic conversation target social goals: increase social inquiries and increase verbal contributions

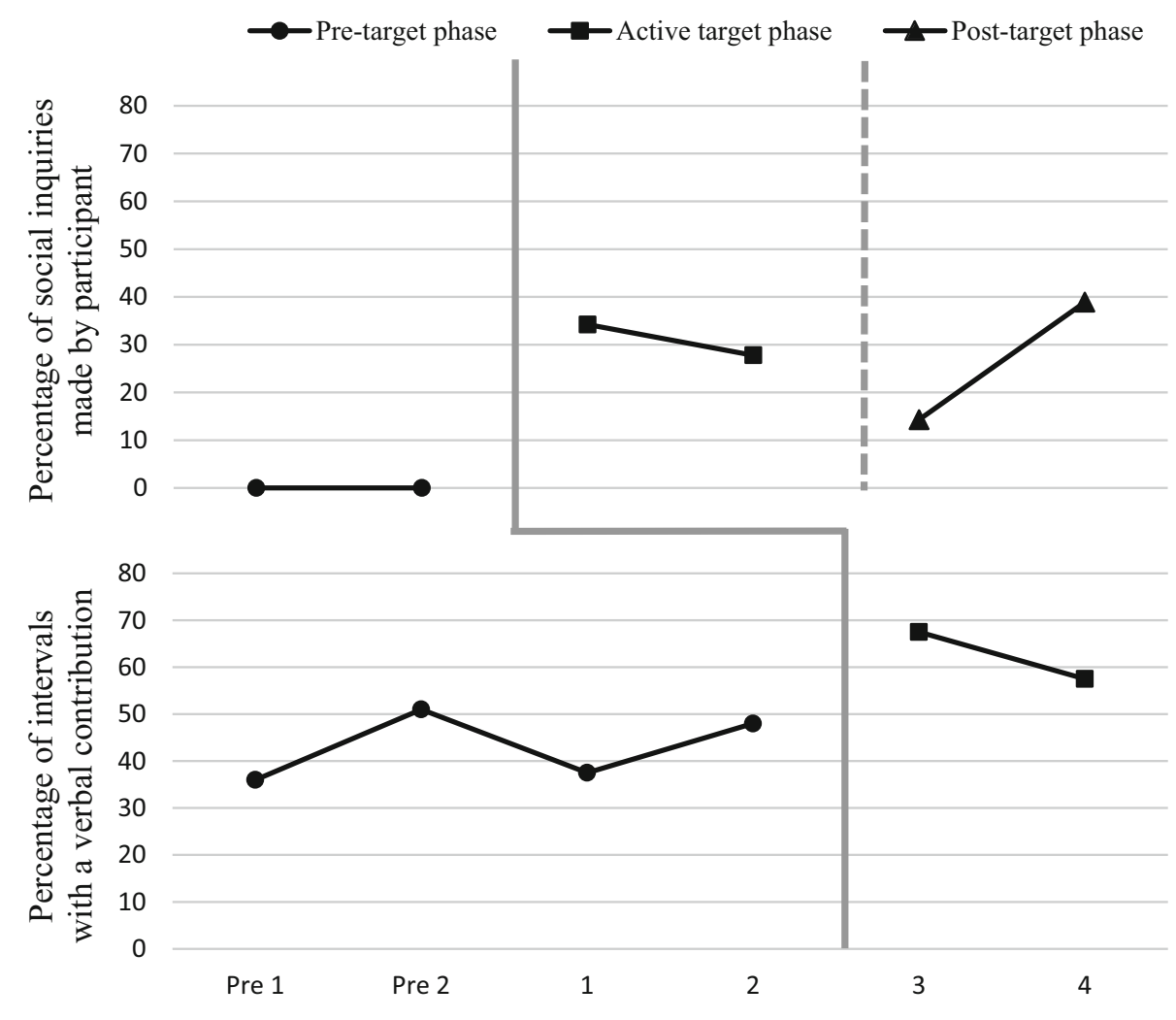

The participants also indicated that they highly enjoyed their time in the groups (mean rating of 8.33 out of 10 , $\mathrm{SD}=1.63$ ). They also endorsed that their social skills and competence improved through participation in the group (mean of 8.17 out of $10, \mathrm{SD}=1.33$ ).

\section{Discussion}

To ascertain meaningful information about social skill improvements from the survey data, the mean of the last two progress meeting data points (meetings 3 and 4) were compared to the mean of both pre-intervention data points. In this preliminary investigation, participants were noted to demonstrate some promising evidence of improvement across several of the utilized parent and adolescent survey report measures. Among measures with corresponding parent and self-report versions, the adolescents consistently rated themselves as more socially competent than their parents rated them at all time points. These findings align with previous studies (e.g. McMahon and Solomon 2015; Lerner et al. 2012) and suggest that in general, adolescents with ASD may overestimate their relative level of social aptitude. Whereas these survey measures assessed important parent and adolescent perspectives on social functioning improvements, the use of data extracted from live conversation probes also contributed valuable information about their social competence profiles. 
Fig. 7 Participant 6's dynamic conversation target goals: increase social inquiries and reduce negative statements

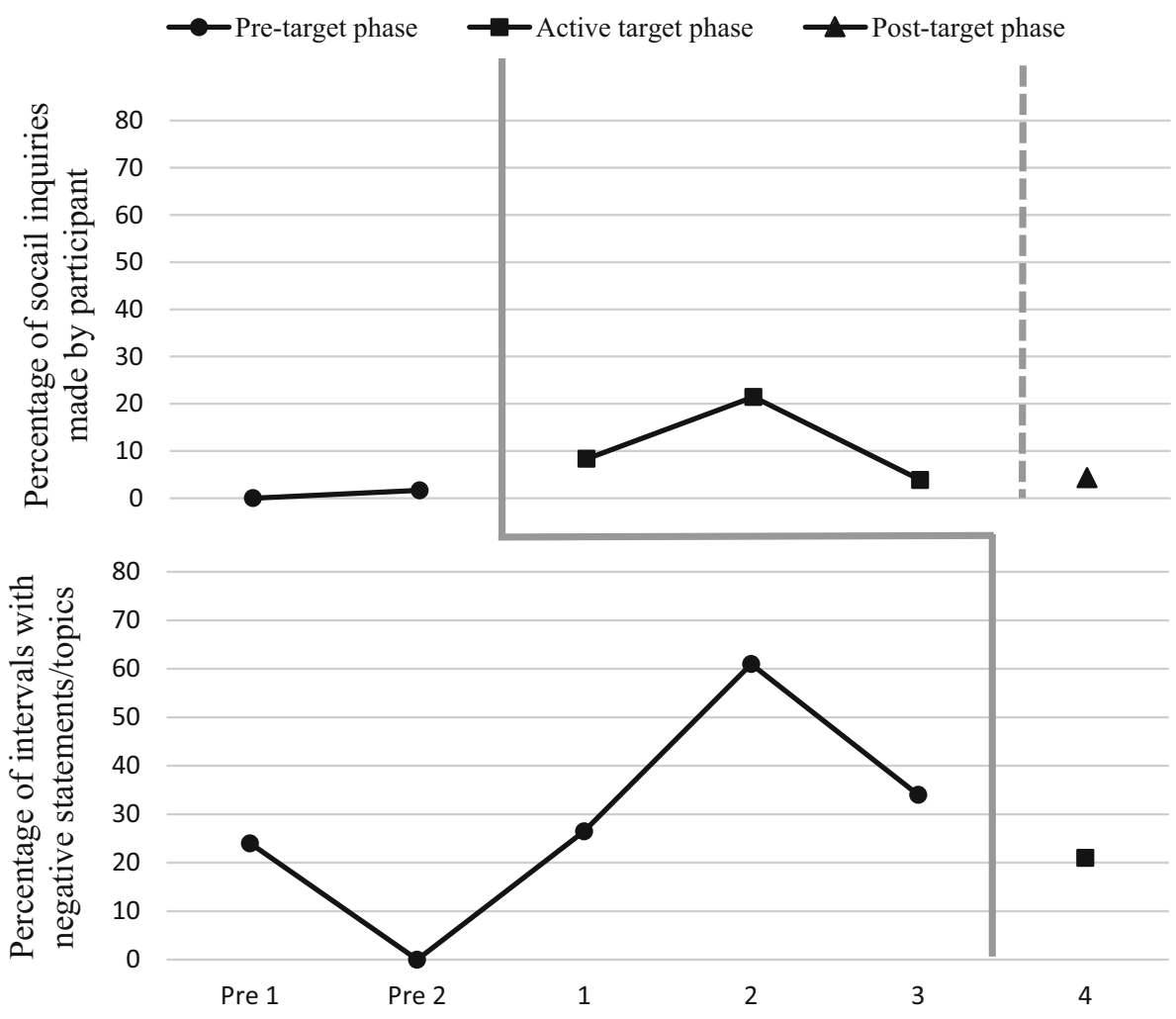

The conversational skill data are indicative of encouraging improvements to a range of individualized social difficulties-making social inquiries, decreasing negative statements, and increasing or decreasing total verbal contributions during social exchanges. These findings varied in terms of the magnitude of the treatment effect, but seem to provide preliminary evidence of the value of incorporating individualized target skills, experiential opportunities, and self-management into a socialization program. The conversational target skill data provides promising evidence of both (a) the potential benefits of individualizing some aspects of a group socialization curriculum and (b) the utility of using serial conversation probes as a novel means to assess social competence improvements.

Dynamic (live) social performance measures are only rarely used in the social skills intervention research literature, with most programs relying on survey measures as their primary outcome measures (Bolte and Diehl 2013; McMahon et al. 2013a). Live measures may yield more ecologically valid data (Elliott and Gresham 1987; McMahon et al. 2013b; Merrell 2001) and are immune or less susceptible to social desirability biases, random responding, and demand characteristic issues that are recognized as limitations to survey measures (Furr and Funder 2007; Moskowitz 1986).

Social competence is perhaps best encapsulated as one's level of success within live, dynamic exchanges with peers. Therefore, it is logical that evaluations of social competence (and the programs that aim to improve such competencies) incorporate live, dynamic performance measures as evaluative strategies. To our knowledge, this preliminary investigation is one of the first socialization interventions to incorporate serial conversation probes to augment the use of more traditional social survey measures when assessing improvements to interpersonal functioning.

Autism spectrum disorder can be conceptualized as a disorder of socialization, with its very diagnostic criteria presupposing impairments in social motivation and functioning (American Psychiatric Association 2013). Because of the pervasive and complex nature of interpersonal vulnerabilities associated with ASD (Bauminger 2002; Bauminger and Kasari 2000), which can often be intertwined with a long history of social rejection or isolation (e.g. Chamberlain et al. 2007), adolescents with ASD are likely to require a unique training program that simultaneously attends to multiple treatment considerations. The diverse profiles of adolescents with ASD create a unique challenge for the development of an effective social skills intervention program (Weiss and Harris 2001; Matson et al. 2007). A program that exclusively focuses on didactic social skills acquisition is unlikely to benefit those with low motivation to engage with others and/or those who only have access to nonreciprocal social partners. On the other hand, an intervention that solely provides a highly motivating experiential social context may be suitable for relatively 
sophisticated individuals, but is unlikely to benefit to those who lack knowledge of basic socialization strategies.

The hybrid experiential and didactic components of the START program were designed to directly address the diverse needs of the population within a low-demand, highmotivation context. The resulting social validity ratings from the parent and participant adolescents of this intervention were quite favorable-possibly because this preliminary evaluation incorporated engaging components similar to existing afterschool clubs and utilized a cohort of peers and social facilitators. Both participants and their parents endorsed a high level of satisfaction with the social group curriculum and the adolescents appeared to build strong group relationships. These observations and feedback are not inconsequential, as an effective social skills curriculum requires strong buy-in from both adolescent and parent stakeholders. Motivation for continued participation is essential, and the described program intentionally embedded several components for boosting and maintaining social interest and camaraderie (i.e., use of college-aged social facilitators, a variety of group activities and games, the provision of snacks, and a hands-on experiential emphasis).

The opportunity to interact with peers and jointly work on social skills in an experiential setting may be preferable to attending a social skills group facilitated solely by adult professionals. Because everyone in the program (including the college-aged social facilitators) jointly completed the selfmanagement tasks and social lessons, there may have also been a minimization of the inherent stigma traditionally associated with having to acknowledge one's social deficits. The intervention setting was designed to closely mirror real-world socialization settings to help build confidence and competence across structured and unstructured social situations.

It should be noted that there were several limitations to the current preliminary investigation. The repeated measure clinical case series component of this investigation was non-experimental in nature, with no contrast group that would allow for controlled comparisons. This limitation is somewhat tempered by the addition of the multiple baseline design for the dynamic conversation probe data, which allowed the participants to serve as their own controls for their individualized target behaviors. Baseline phases were staggered across participants and behaviors, ranging from one to five time-points. Multiple baseline designs are considered a rigorous single-case experimental design (Barlow et al. 2009).

In the current study, the small sample size also limits the generalization of the preliminary findings. While some promising initial outcomes were observed among our small sample, a larger pool of participants is required to identify how universally applicable this intervention package would be to the broader population of adolescents with ASD. Additionally, no data was collected on the quality of the participants' interactions in real world social settings during or after the conclusion of the program. Such information is necessary for a comprehensive understanding of the generalized effects of program participation. To address these concerns, a randomized controlled trial is currently underway to further investigate the merits of the START program with increased methodological rigor, a significantly increased sample size, and long-term follow-up data.

Our initial findings suggest that the START social skills program may serve as a promising intervention for improving the social competence of adolescents with ASD. Based on our preliminary data, adolescents who participated in our multi-component social club appear to experience indications of improvement to social functioning, as measured by survey and live conversational measures. Following participation, these individuals seem to be equipped with an improved social skill set and associated level of social motivation, informed by an increased understanding of social rules and expectations. Social competence is essential at all ages, but perhaps more so during the critical transition to young adulthood (Hendricks and Wehman 2009). This time period is often accompanied by a significant decrease in external support as adolescents graduate from high school and age out of federally-mandated special education services (Camarena and Sarigiani 2009). Therefore, prior to this transitional time point, it may be crucial to equip adolescents with ASD with a core set of social competencies to maximize their long-term quality of life and create strong opportunities for increased independent living. Ultimately, interpersonal aptitude largely governs their ultimate level of success in many of life's pursuits, including the obtainment of desirable employment, development of meaningful friendships, and establishment of romantic relationships (Burt et al. 1991; Eaves and Ho 2008; Hurlbutt and Chalmers 2002).

Acknowledgments The authors would like to acknowledge all of the adolescents and parents that participated in this research, along with all of the undergraduate research assistants that made this project possible.

Author Contributions TV and AM jointly developed the START intervention model and conducted the preliminary evaluation trial. JK assisted with intervention model development. VW served as the lead research assistant on this project and assisted with data input, organization, and analysis. All authors contributed to significant portions of the manuscript drafting and revision process. 


\section{Appendix 1: Social Competency and Motivation Scale}

Instructions: For each question, please indicate how much you agree with each of the following statements by selecting ONE of the following choices. If you are unsure, please make your best guess.

\begin{tabular}{|c|c|c|c|c|c|}
\hline & Not at all & Rarely & Sometimes & Usually & Almost Always \\
\hline My child is comfortable in social situations & 1 & 2 & 3 & 4 & 5 \\
\hline My child knows how to interact with an unfamiliar person & 1 & 2 & 3 & 4 & 5 \\
\hline My child is willing to go out in public by him/herself & 1 & 2 & 3 & 4 & 5 \\
\hline My child knows how to make friends with other individuals his/her age & 1 & 2 & 3 & 4 & 5 \\
\hline My child makes eye contact with people when talking to them & 1 & 2 & 3 & 4 & 5 \\
\hline My child maintains conversations by asking questions & 1 & 2 & 3 & 4 & 5 \\
\hline My child maintains conversations by making comments & 1 & 2 & 3 & 4 & 5 \\
\hline My child stays on topic during conversations & 1 & 2 & 3 & 4 & 5 \\
\hline My child brings up appropriate conversation topics & 1 & 2 & 3 & 4 & 5 \\
\hline My child greets others appropriately & 1 & 2 & 3 & 4 & 5 \\
\hline My child introduces him/herself appropriately & 1 & 2 & 3 & 4 & 5 \\
\hline My child ends conversations appropriately & 1 & 2 & 3 & 4 & 5 \\
\hline My child uses appropriate voice volume/rate intonation when speaking & 1 & 2 & 3 & 4 & 5 \\
\hline My child exhibits appropriate facial expressions when talking with others & 1 & 2 & 3 & 4 & 5 \\
\hline My child verbally expresses empathy for others & 1 & 2 & 3 & 4 & 5 \\
\hline My child compliments others & 1 & 2 & 3 & 4 & 5 \\
\hline My child uses age-appropriate humor & 1 & 2 & 3 & 4 & 5 \\
\hline My child has an interest in other people & 1 & 2 & 3 & 4 & 5 \\
\hline My child wants to have friends & 1 & 2 & 3 & 4 & 5 \\
\hline My child knows how to behave when he/she is at a party & 1 & 2 & 3 & 4 & 5 \\
\hline My child prefers to be with other people during his/her free time & 1 & 2 & 3 & 4 & 5 \\
\hline My child loves to talk to other people & 1 & 2 & 3 & 4 & 5 \\
\hline My child likes to learn about the experiences of other people & 1 & 2 & 3 & 4 & 5 \\
\hline My child feels comfortable going out with peers in group outings & 1 & 2 & 3 & 4 & 5 \\
\hline My child goes over to friends' houses or has them come to our house & 1 & 2 & 3 & 4 & 5 \\
\hline My child is skilled in maintaining relationships over time & 1 & 2 & 3 & 4 & 5 \\
\hline
\end{tabular}

\section{References}

American Psychiatric Association. (2013). Diagnostic and statistical manual of mental disorders: DSM-5. Washington, DC: American Psychiatric Association.

Baker, A. C., Jensen, P. J., \& Kolb, D. A. (2002). Conversational learning: An experiential approach to knowledge creation. Portsmouth, NH: Greenwood Publishing Group.

Barlow, M. D., Nock, M., \& Hersen, M. (2009). Single case experimental designs: Strategies for studying behavior for change (No. Sirsi) i9780205474554).

Baron-Cohen, S. (1995). Theory of mind and face-processing: How do they interact in development and psychopathology? In Developmental psychopathology, Vol. 1: Theory and methods (pp. 343-356). Oxford: John Wiley \& Sons.

Bauminger, N. (2002). The facilitation of social-emotional understanding and social interaction in high-functioning children with autism: Intervention outcomes. Journal of Autism and Developmental Disorders, 32(4), 283-298. doi:10.1023/A:1016378718278.

Bauminger, N., \& Kasari, C. (2000). Loneliness and friendship in high-functioning children with autism. Child Development, 71(2), 447-456. doi:10.1111/1467-8624.00156.
Blair, R. J. R., Frith, U., Smith, N., Abell, F., \& Cipolotti, L. (2002). Fractionation of visual memory: Agency detection and its impairment in autism. Neuropsychologia, 40(1), 108-118.

Bolte, E. E., \& Diehl, J. J. (2013). Measurement tools and target symptoms/skills used to assess treatment response for individuals with autism spectrum disorder. Journal of Autism and Developmental Disorders, 43(11), 2491-2501.

Burleson, B. R., Applegate, J. L., Burke, J. A., Clark, R. A., Delia, J. G., \& Kline, S. L. (1986). Communicative correlates of peer acceptance in childhood. Communication Education, 35(4), 349-361.

Burt, D. B., Fuller, S. P., \& Lewis, K. R. (1991). Brief report: Competitive employment of adults with autism. Journal of Autism and Developmental Disorders, 21(2), 237-242. doi:10. 1007/BF02284763.

Camarena, P. M., \& Sarigiani, P. A. (2009). Postsecondary educational aspirations of high-functioning adolescents with autism spectrum disorders and their parents. Focus of Autism and Other Developmental Disabilities, 24(2), 115-128. doi:10.1177/ 1088357609332675.

Carr, M. E., Moore, D. W., \& Anderson, A. (2014). Self-management interventions on students with autism: A meta-analysis of singlesubject research. Exceptional Children, 81(1), 28-44. 
Chamberlain, B., Karasi, C., \& Rotheram-Fuller, E. (2007). Involvement or isolation? The social networks of children with autism in regular classrooms. Journal of Autism and Developmental Disorders, 37(2), 230-242. doi:10.1007/s10803-006-0164-4.

Church, C., Alisanski, S., \& Amanullah, S. (2000). The social, behavioral, and academic experiences of children with asperger syndrome. Focus on Autism and Other Developmental Disabilities, 15(1), 12-20. doi:10.1177/108835760001500102.

Constantino, J., \& Gruber, C. (2005). Social responsiveness scale. Los Angeles: Western Psychological Services.

DiCicco-Bloom, E., Lord, C., Zwaigenbaum, L., Courchesne, E., Dager, S. R., Schmitz, C., \& Young, L. J. (2006). The developmental neurobiology of autism spectrum disorder. The Journal of Neuroscience, 26(26), 6897-6906.

Doggett, R. A., Krasno, A. M., Koegel, L. K., \& Koegel, R. L. (2013). Acquisition of multiple questions in the context of social conversation in children with autism. Journal of Autism and Developmental Disorders,. doi:10.1007/s10803-012-1749-8.

Eaves, L. C., \& Ho, H. H. (2008). Young adult outcome of autism spectrum disorders. Journal of Autism and Developmental Disorders, 38(4), 739-747. doi:10.1007/s10803-007-0441-x.

Elder, L. M., Caterino, L. C., Chao, J., Shacknai, D., \& DeSimone, G. (2006). The efficacy of social skills treatment for children with Asperger syndrome. Education \& Treatment of Children, 29(4), 635-663.

Elliott, S. N., \& Gresham, F. M. (1987). Children's social skills: Assessment and classification practices. Journal of Counseling \& Development, 66(2), 96-99.

Engström, I., Ekström, L., \& Emilsson, B. (2003). Psychosocial functioning in a group of swedish adults with asperger syndrome or high-functioning autism. Autism, 7(1), 99-110.

Furr, R., \& Funder, D. (2007). Behavioral observation. In Handbook of research methods in personality psychology (pp. 273-291). New York: The Guilford Press.

Ghaziuddin, M., \& Gerstein, L. (1996). Pedantic speaking style differentiates Asperger syndrome from high-functioning autism. Journal of Autism and Developmental Disorders, 26(6), 585-595.

Ghaziuddin, M., Ghaziuddin, N., \& Greden, J. (2002). Depression in persons with autism: Implications for research and clinical care. Journal of Autism and Developmental Disorders, 32(4), 299-306. doi:10.1023/A:1016330802348.

Grainger, C., Williams, D. M., \& Lind, S. E. (2014). Metacognition, metamemory, and mindreading in high-functioning adults with autism spectrum disorder. Journal of Abnormal Psychology, 123(3), 650 .

Gresham, F. M., \& Elliott, S. N. (2008). Social skills improvement system (SSIS) Rating Scales. Minneapolis, MN: Pearson.

Gutstein, S. E., \& Whitney, T. (2002). Asperger syndrome and the development of social competence. Focus on Autism and Other Developmental Disabilities, 17(3), 161-171. doi:10.1177/ 10883576020170030601.

Hendricks, D. R., \& Wehman, P. (2009). Transition from school to adulthood for youth with autism spectrum disorders. Focus on Autism and Other Developmental Disabilities, 24(2), 77-88. doi: $10.1177 / 1088357608329827$.

Howlin, P. (2000). Outcome in adult life for more able individuals with autism or asperger syndrome. Autism, 4(1), 63-83.

Hurlbutt, K., \& Chalmers, L. (2002). Adults with autism speak out: Perceptions of their life experiences. Focus on Autism and Other Developmental Disabilities, 17(2), 103-111. doi:10.1177/ 10883576020170020501.

Jones, W., \& Klin, A. (2009). Heterogeneity and homogeneity across the autism spectrum: The role of development. Journal of the American Academy of Child \& Adolescent Psychiatry, 48(5), $471-473$
Kim, J. A., Szatmari, P., Bryson, S. E., Streiner, D. L., \& Wilson, F. J. (2000). The prevalence of anxiety and mood problems among children with autism and Asperger syndrome. Autism, 4(2), 117-132. doi:10.1177/1362361300004002002.

Koegel, L. K., Koegel, R. L., Hurley, C., \& Frea, W. D. (1992). Improving social skills and disruptive behavior in children with autism through self-management. Journal of Applied Behavior Analysis, 25(2), 341-353.

Kolb, D. A. (2014). Experiential learning: Experience as the source of learning and development (2nd ed.). Upper Saddle River, NJ: Pearson Education.

Kolb, D. A., Boyatzis, R. E., \& Mainemelis, C. (2001). Experiential learning theory: Previous research and new directions. In $\mathrm{R}$. J. Sternberg \& L. F. Zhang (Eds.), Perspectives on thinking, learning, and cognitive styles (pp. 227-247). Mahwah, NJ: Lawrence Erlbaum.

Landa, R. (2000). Social language use in Asperger syndrome and high-functioning autism. In A. Klin, F. R. Volkmar, \& S. S. Sparrow (Eds.), Asperger syndrome. New York: Guilford Press.

Laugeson, E. A., Frankel, F., Gantman, A., Dillon, A. R., \& Mogil, C. (2012). Evidence-based social skills training for adolescents with autism spectrum disorders: The UCLA PEERS program. Journal of Autism and Developmental Disorders, 42(6), 1025-1036. doi:10.1007/s10803-011-1339-1.

Lee, S., Simpson, R. L., \& Shogren, K. A. (2007). Effects and implications of self-management for students with autism: A meta-analysis. Focus on Autism and Other Developmental Disabilities, 22(1), 2-13. doi:10.1177/10883576070220010101.

Lerner, M. D., Calhoun, C. D., Mikami, A. Y., \& De, L. R. (2012). Understanding parent-child social informant discrepancy in youth with high functioning autism spectrum disorders. Journal of Autism and Developmental Disorders, 42(12), 2680-2692. doi:10.1007/s10803-012-1525-9.

Lord, C., Rutter, M., DiLavore, P. C., Risi, S., Gotham, K., \& Bishop, S. (2012). Autism diagnostic observation schedule (2nd ed.). Torrance, CA: Western Psychological Services.

Matson, J. L., Matson, M. L., \& Rivet, T. T. (2007). Social-skills treatments for children with autism spectrum disorders. Behavior Modification, 31(5), 682-707. doi:10.1177/0145445507301650.

McMahon, C. M., Lerner, M. D., \& Britton, N. (2013a). Group-based social skills interventions for adolescents with higher-functioning autism spectrum disorder: A review and looking to the future. Adolescent Health, Medicine and Therapeutics, 4, 23.

McMahon, C. M., \& Solomon, M. (2015). Brief Report: Parentadolescent informant discrepancies of social skill importance and social skill engagement for higher-functioning adolescents with autism spectrum disorder. Journal of Autism and Developmental Disorders, 45(10), 3396-3403.

McMahon, C. M., Vismara, L. A., \& Solomon, M. (2013b). Measuring changes in social behavior during a social skills intervention for higher-functioning children and adolescents with autism spectrum disorder. Journal of Autism and Developmental Disorders, 43(8), 1843-1856.

Merrell, K. W. (2001). Assessment of children's social skills: Recent developments, best practices, and new directions. Exceptionality, 9(1-2), 3-18.

Miller, A.R., Vernon, T.W., Wu, V., Russo, K. (2014) Social skill group interventions for adolescents with autism spectrum disorders: A systematic review. Review Journal of Autism and Developmental Disorders.

Moskowitz, D. S. (1986). Comparison of self-reports, reports by knowledgeable informants, and behavioral observation data. Journal of Personality, 54(1), 294-317.

Nadig, A., Lee, I., Singh, L., Bosshart, K., \& Ozonoff, S. (2010). How does the topic of conversation affect verbal exchange and eye 
gaze? A comparison between typical development and highfunctioning autism. Neuropsychologia, 48(9), 2730-2739.

National Autism Center. (2009). National Standards Report. Randolph, MA: Self-published.

Newcomb, A. F., Bukowski, W. M., \& Pattee, L. (1993). Children's peer relations: A meta-analytic review of popular, rejected, neglected, controversial, and average sociometric status. Psychological Bulletin, 113(1), 99.

Newman, B., \& Ten Eyck, P. (2005). Self-management of initiations by students diagnosed with autism. Analysis of Verbal Behavior, $21,117-122$.

Ojanen, T., Sijtsema, J. J., Hawley, P. H., \& Little, T. D. (2010). Intrinsic and extrinsic motivation in early adolescents' friendship development: Friendship selection, influence, and prospective friendship quality. Journal of Adolescence, 33(6), 837-851.

Ollendick, T. H., Weist, M. D., Borden, M. C., \& Greene, R. W. (1992). Sociometric status and academic, behavioral, and psychological adjustment: A five-year longitudinal study. Journal of Consulting and Clinical Psychology, 60, 80-87.

Ozonoff, S., \& Miller, J. N. (1995). Teaching theory of mind: A new approach to social skills training for individuals with autism. Journal of Autism and Developmental Disorders, 25(4), 415-433.

Palmen, A., Didden, R., \& Arts, M. (2008). Improving question asking in high-functioning adolescents with autism spectrum disorders: Effectiveness of small-group training. Autism, 12(1), 83-98. doi:10.1177/1362361307085265.

Parker, J., \& Asher, S. (1987). Peer relations and later personal adjustment: Are low accepted children "at risk"? Psychological Bulletin, 102, 357-389.
Reichow, B., Steiner, A. M., \& Volkmar, F. (2012). Social skills groups for people aged 6 to 21 with autism spectrum disorders (ASD). The Cochrane Database of Systematic Reviews, 7, 1. doi:10.1002/14651858.CD008511.pub2.

Rutter, M., Le Couteur, A., \& Lord, C. (2003). Autism diagnostic interview, revised. Torrance, CA: Western Psychological Services.

Starr, E., Szatmari, P., Bryson, S., \& Zwaigenbaum, L. (2003). Stability and change among high-functioning children with pervasive developmental disorders: A 2-year outcome study. Journal of Autism and Developmental Disorders, 33(1), 15-22.

Webb, B. J., Miller, S. P., Pierce, T. B., Strawser, S., \& Jones, W. P. (2004). Effects of social skill instruction for high-functioning adolescents with autism spectrum disorders. Focus on Autism and Other Developmental Disabilities, 19(1), 53-62. doi:10. 1177/10883576040190010701.

Weiss, M. J., \& Harris, S. L. (2001). Teaching social skills to people with autism. Behavior Modification, 25(5), 785-802. doi:10. 1177/0145445501255007.

White, S. W., Koenig, K., \& Scahill, L. (2010). Group social skills instruction for adolescents with high-functioning autism spectrum disorders. Focus on Autism and Other Developmental Disabilities, 25(4), 209-219. doi:10.1177/1088357610380595.

Williams, D. M., Lind, S. E., \& Happé, F. (2009). Metacognition may be more impaired than mindreading in autism. Behavioral and Brain Sciences, 32(02), 162-163. 